\title{
Microsporidiosis of Tachinaephagus zealandicus Ashmead (Hymenoptera: Encyrtidae)
}

\author{
Maria A Ferreira de Almeida, Christopher J Geden*, Carl K Boohene*, James J Becnel*, \\ Angelo Pires do Prado/ ${ }^{+}$
}

\begin{abstract}
Departamento de Parasitologia, Instituto de Biologia, Unicamp, Caixa Postal 6109, 13083-970 Campinas, SP, Brasil *US Department of Agriculture, Agricultural Research Service, Center for Medical, Agricultural and Veterinary Entomology, Florida, USA

An undescribed microsporidium was found infecting Tachinaephagus zealandicus, a gregarious parasitoid that attacks third instar larvae of muscoid flies. Spores were present in all body regions and in all stages of development. Infected adults contained an average of $3.75 \times 10^{5}$ spores, and the pathogen was vertically transmitted to progeny. Infected female adults were fed either rifampicin or albendazole mixed with honey to determine the effectiveness of these drugs in preventing vertical transmission. After eight days of feeding on rifampicin the parasitoids produced progeny of which only 37\% were infected. In contrast, albendazole-treated and untreated females produced progeny that were $97 \%$ and $100 \%$ infected, respectively. Healthy and infected colonies were established and studies were conducted to determine the mechanisms of transmission. It was observed that the efficiency of vertical (maternal) transmission was $96.3 \%$. Uninfected parasitoid immatures also became infected when they shared superparasitized hosts with infected immatures. The method of transmission within superparasitized hosts is not known.
\end{abstract}

Key words: Tachinaephagus zealandicus - microsporidium - albendazole - rifampicin - maternal transmission

Tachinaephagus zealandicus is a gregarious parasitoid that attacks third instar larvae of muscoid flies. Available evidence indicates that this species is endemic to the Southern Hemisphere (Olton 1971). During a visit to the US Department of Agriculture's Center for Medical, Agricultural and Veterinary Entomology, located in Gainesville, Florida, our attention was called by Dr CJ Geden to the possibility of infection of our T. zealandicus colony by a microsporidium. Insects are the most important hosts of microsporidia and approximately half the number of species are parasites of insects (Larsson 1988). These protozoan pathogens can cause profound losses in fitness and searching ability of parasitoids within a short time after establishment from field populations as described for colonies of Muscidifurax raptor by Geden et al. (1992). The examination of host flies from the field and experimental transmissions from parasitoids to flies would be required to determine whether infections of hosts could be involved in the epizootiology of this pathogen in nature (ZchoriFein et al. 1992), but according to Geden et al. (1995) the microsporidium Nosema muscidifuracis described infecting $M$. raptor was transovarially transmitted and the muscoid host was not infected.

We present herein the first report of a microsporidian associated with $T$. zealandicus, an investigation of the mechanisms of transmission of this pathogen, and a tentative method of preventing vertical transmission to obtain uninfected individuals.

This work was supported by Fapesp (Fundação de Amparo à Pesquisa do Estado de São Paulo), Process no. 96/1570-8.

${ }^{+}$Corresponding author. Fax: +55-19-289.3124. E-mail: apprado@unicamp.br

Received 16 April 2001

Accepted 11 March 2002

\section{MATERIALS AND METHODS}

Insect colonies - T. zealandicus were from a colony originally established from samples collected from a poultry farm in Santa Cruz da Conceição, São Paulo, Brazil, and had been maintained on Chrysomya putoria (Diptera: Calliphoridae) for 14 generations at the time of testing.

The parasitoids were maintained at $25 \pm 1{ }^{\circ} \mathrm{C}, 60 \pm 10 \%$ RH, with a photoperiod of 12L:12D. Honey and water were provided to the insects and $C$. putoria larvae were exposed to 2-days old females. Parasitized pupae were held at $22 \pm 1{ }^{\circ} \mathrm{C}, 60 \pm 10 \% \mathrm{RH}$.

C. putoria and Sarcophaga bullata (Diptera: Sarcophagidae) larvae were reared using the diet described by Leal et al. (1982), and adults were held under the environmental conditions described above. Flies were given water and sugar ad libitum and periodically given liver for egg maturation and oviposition.

Voucher specimens of infected parasitoids have been deposited for identification/description in the US Department of Agriculture, Agricultural Research Service, Center for Medical, Agricultural and Veterinary Entomology, Gainesville, Florida, USA.

Pathogen diagnosis and spore counts - Spore counts of parasitoid larvae, pupae and adults stages $(n=10)$ were made using the method of Cantwell (1970). Newly deposited parasitoid eggs $(n=10)$ removed from host pupae were squashed, stained by Giemsa, and observed for the presence of spores. Tissues of fly hosts were also examined for the presence of spores, and adult parasitoids were dissected to examine infection in different tissues. Spores were counted using a hemacytometer and measured with a split image micrometer (Undeen \& Vavra 1997). To verify the nature of the infections in T. zealandicus, specimens were prepared for examination with the electron microscope as follows. Adults were fixed for $2 \mathrm{~h}$ at room temperature in $2.5 \%$ glutaraldehyde in $0.1 \mathrm{M}$ cacodylate buffer $(\mathrm{pH}=7.3)$ and postfixed in $2 \%$ aqueous osmium 
tetroxide. The tissues were dehydrated through an ascending ethanol series and embedded in Epon-Araldite. Thin sections, stained in uranyl acetate and lead citrate, were examined and photographed at $75 \mathrm{kV}$.

Drug treatment - About 300 female parasitoids within $5 \mathrm{~h}$ of emergence were separated in three groups of 100 females each one, that were kept in three different cages maintained at $20^{\circ} \mathrm{C}, 60 \pm 10 \% \mathrm{RH}$. Each group received one pattern of drug treatment: treatment I (honey with $3 \%$ rifampicin), treatment II (honey with 3\% albendazole), and treatment III (honey-only). Preliminary testing established that this was the upper limit of rifampicin that the parasitoids could tolerate without causing unacceptably high mortality. Two days after starting drug treatment, cages were removed to another rearing chamber set at $25^{\circ} \mathrm{C}, 60 \pm$ $10 \% \mathrm{RH}$, where the females were provided, during $24 \mathrm{~h}$, with host larvae to parasitize and drug treatment. After this period of exposure, host larvae were removed from the presence of females and these were maintained again at $20^{\circ} \mathrm{C}, 60 \pm 10 \% \mathrm{RH}$ plus drug treatment. The same procedure was repeated 6 and 8 days after starting the drug treatment. Parasitized hosts were maintained at $25^{\circ} \mathrm{C}, 60 \pm$ $10 \% \mathrm{RH}$ and about 25 days after each exposure started the emergence of the new progeny. Batches of about 30 newly emerged individuals of each treatment were squashed and examined for infection. All these procedures (but using only rifampicin) were repeated in the five subsequent generations of parasitoids in order to establish a healthy colony.

Efficiency of maternal transmission within superparasitized hosts - Eighty individual larvae of $S$. bullata were placed in $30 \mathrm{ml}$ clear plastic cups covered by snap-on plastic lids with screened openings and exposed to female parasitoids in the following four combinations (20 cups of larvae/combination): (1) 2 infected females - 8 $\mathrm{h}$; (2) 2 uninfected females $-8 \mathrm{~h}$; (3) 2 uninfected females - $4 \mathrm{~h}$ then 2 infected females - $4 \mathrm{~h}$; (4) 2 infected and 2 uninfected females $-8 \mathrm{~h}$. Adult progeny were counted and assessed for infection status. Differences in the number of progeny infected with the microsporidium for each combination were evaluated by ANOVA using GLM Procedure of SAS (P < 0.05) (SAS Institute 1992).

\section{RESULTS}

Pathogen diagnosis and spore counts - Dissection and examination of adult parasitoids revealed that the infections were systemic, with spores observed in gut tissue, malphigian tubules, fat body, ovaries and muscle. Spores appeared to be present inside newly deposited eggs of $T$. zealandicus, although the numbers observed were very small $(<10$ spores/egg). Spores in adult parasitoids measured $4.16 \pm 0.12 \times 2.05 \pm 0.07 \mu \mathrm{m}(\mathrm{n}=16)$. Diplokaryotic stages and diplokaryotic spores containing a polar filament (Figure) verified that the parasite was a species of microsporidia with the basic features of the genus Nosema (Sprague et al. 1992). Additional morphological and molecular studies are in progress to formally describe and name this new species. The number of spores increased considerably as parasitoids passed from one stage to another (Table I). No spores were observed in tissues of the host flies (S. bullata and C. putoria).

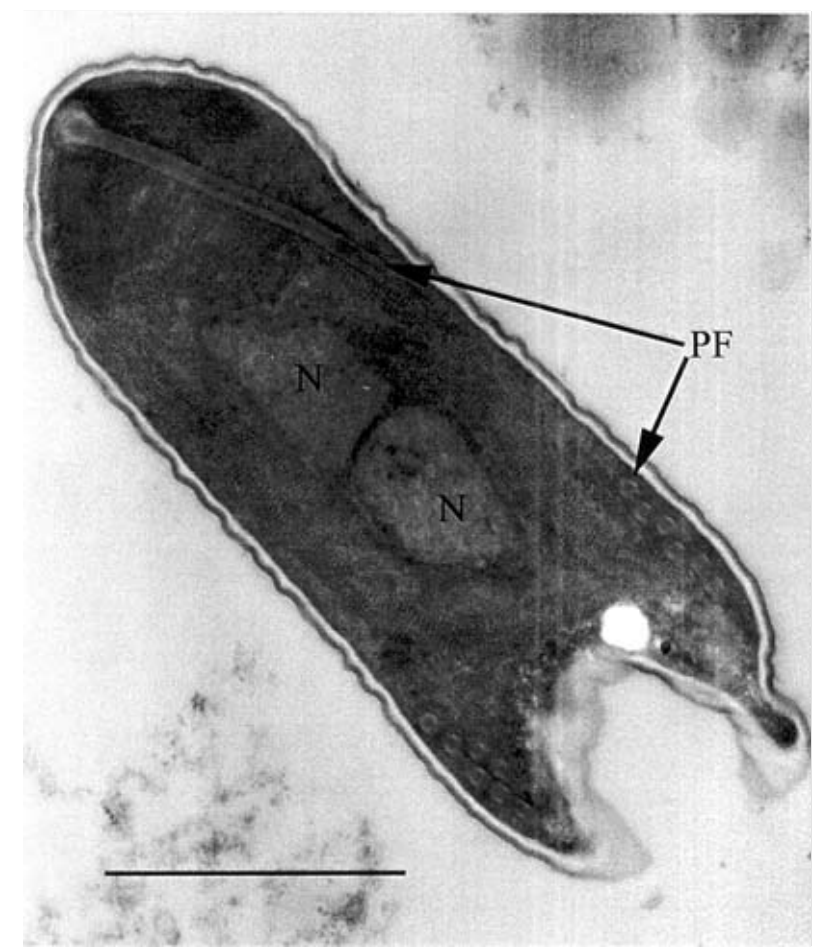

Electron micrograph of a mature diplokaryotic spore from Tachinaephagus zealandicus demonstrating the polar filament apparatus. N: nucleus; PF: polar filament. Bar $=1 \mu \mathrm{m}$

TABLE I

Density of microsporidian spores observed in infected stages of development of Tachinaephagus zealandicus

\begin{tabular}{lc}
\hline Stage of development & $\begin{array}{c}\text { Mean no. of spores } \\
\text { per parasitoid }\end{array}$ \\
\hline Egg inside the host & 6.0 \\
Larvae & $9.5 \times 10^{4}$ \\
Pupae & $1.40 \times 10^{5}$ \\
Adults & $3.75 \times 10^{5}$ \\
\hline
\end{tabular}

Drug treatment - The results of the drug treatment applied to infected females of $T$. zealandicus indicated that infection of their newly emerged progeny was partially controlled (63\% of progeny uninfected) when females received rifampicin mixed with honey as food, ad libitum for at least 8 days (Table II). All the progeny from the albendazole-treated and honey-only-treated parasitoids were infected, as were those of the rifampicin-treated parasitoids in the first two exposures to host larvae (days 2 and 6 post-treatment).

Efficiency of maternal transmission within superparasitized hosts - When individual host larvae were exposed to two infected parasitoids for $8 \mathrm{~h}$ the rate of maternal transmission was $96.3 \%$ (Table III). None of the progeny from the uninfected parasitoids were infected. When hosts were exposed to equal numbers of infected and uninfected parasitoids, whether sequentially or simultaneously, the rate of infection among progeny was 


\section{TABLE II}

Effect of albendazole and rifampicin treatment on prevalence of microsporidial infection in progeny of Tachinaephagus zealandicus

Number of days Percentage of 30 examined individuals of drug treatment progeny infected when parents given drug

\begin{tabular}{cccc}
\cline { 2 - 4 } & Control & Albendazole & Rifampicin \\
\hline 2 & 100 & 100 & 100 \\
6 & 100 & 100 & 100 \\
8 & 100 & 97 & 37 \\
\hline
\end{tabular}

Drugs mixed with honey and given to adult female parasitoids ad libitum starting on the day of emergence, and their newly emerged progeny were examined for infection 25 days (developmental time for $T$. zealandicus kept in $25^{\circ} \mathrm{C}$ ) after exposure.

TABLE III

Progeny production and infection rates of Tachinaephagus zealandicus progeny reared from individual Sarcophaga bullata larvae exposed to microsporidium-infected and/or uninfected female parasitoids

\begin{tabular}{|c|c|c|}
\hline $\begin{array}{l}\text { Infection status } \\
\text { of female parasitoids } \\
\text { (exposure time) }\end{array}$ & $\begin{array}{c}\text { Mean }(\mathrm{SE}) \\
\text { parasitoid } \\
\text { progeny/host }\end{array}$ & $\begin{array}{c}\text { Mean (SE) \% progeny } \\
\text { infected with the } \\
\text { microsporidium }\end{array}$ \\
\hline 2 infected (8 h) & $42.5(4.67)$ & $96.3(2.72)$ \\
\hline 2 uninfected $(8 \mathrm{~h})$ & $40.9(4.41)$ & $0.0(0.0)$ \\
\hline $\begin{array}{l}2 \text { uninfected }(4 \mathrm{~h}) \text { then } \\
2 \text { infected }(4 \mathrm{~h})\end{array}$ & $52.3(4.00)$ & $83.2(5.57)$ \\
\hline $\begin{array}{l}2 \text { uninfected and } \\
2 \text { infected }(8 \mathrm{~h})\end{array}$ & $55.0(2.52)$ & $82.5(6.32)$ \\
\hline ANOVA F & $3.27^{a}$ & $82.02^{b}$ \\
\hline
\end{tabular}

Results of one-way ANOVA's $(a$ : $\mathrm{P} \leq 0.05 ; b$ : $\mathrm{P} \leq 0.01 ; n s: \mathrm{P}>$ $0.05) ; \mathrm{N}=20$ larvae per treatment

about $83 \%$, indicating that horizontal transmission occurred within superparasitized hosts. The number of progeny produced per larva ranged from 40.9 to 55 across the treatments and did not appear to vary with the infection status of the parents.

\section{DISCUSSION}

Since 1998, when a colony of T. zealandicus was established in our laboratory we have studied this parasitoid and some aspects of its biology. Our investigations showed that this colony was partially infected by a microsporidium that appears to belong to the genus Nosema. All microsporidia are obligatory intracellular organisms, multiplying in the host cells in the form of small paucinucleate meronts or plasmodia (Becnel \& Andreadis 1999). Excessive mortality, reduced longevity, or reduced fecundity are sometimes the indications of a microsporidium in laboratory-reared insects (Undeen \& Vávra 1997).

There are some similarities and differences between the disease studied here and N. muscidifuracis infecting M. raptor (Becnel \& Geden 1994, Geden et al. 1995). Maternal transmission is an important aspect of both disease systems, although the very small numbers of spores present in newly deposited eggs of $T$. zealandicus, could have represented adhesions on the outer surface of the chorion. The same investigation showed that spores of $N$. muscidifuracis within $M$. raptor eggs were revealed only after crushing them; no spores were observed adhering to the outside of the egg and also no spores were observed in the remains of hosts that were attacked by infected parasitoids (Zchori-Fein et al. 1992). Another similarity between the diseases in $M$. raptor and $T$. zealandicus is the increase in spore loads with successive developmental stages of the host parasitoid (Table I). For example, $M$. raptor females contained an average of $1.8 \times 10^{4}$ spores per parasitoid at emergence, and infection intensity increased to $2.7 \times 10^{4}$ spores after 5-7 days (Zchori-Fein et al. 1992). For T. zealandicus we found that adults contain ca. $3.75 \times 10^{5}$ spores. In addition, our results are similar to those with $N$. muscidifuracis in that the host fly does not appear to become infected (Geden et al. 1995).

Our results showed that treatment using albendazole was not effective compared to treatment with rifampicin (Table II). Both of these drugs are known to have activity against other microsporidia (Haque et al. 1993, Sheetz et al. 1997). After obtaining an uninfected colony we conducted an experiment to investigate the efficiency of transmission of this pathogen. The efficiency of the maternal transmission by infected females was very high (96.3\%) (Table III) and is close to the $100 \%$ transmission efficiency typically observed with transmission of $N$. muscidifuracis (Geden et al. 1995). Further experiments would be required to evaluate the role of males in possible paternal and venereal transmission, but neither of the routes of infection is likely to occur (Zchori-Fein et al. 1992, Geden et al. 1995).

High rates of infection of progeny (ca. 83\%) were observed when larvae were exposed to equal numbers of infected and uninfected females (Table III). With $T$. zealandicus the two mechanisms of transmission via cannibalism described by Geden et al. (1995) probably do not occur because this species is a gregarious parasitoid and does not appear to host-feed (Olton 1971). There are other possible mechanisms for horizontal infection in $T$. zealandicus. Although larval cannibalism is unlikely, it is possible that infected eggs or larvae could die within the host and release spores that could be ingested by uninfected larvae in the same host. A second possible mechanism could be the deposition of spores into the host hemolymph at the time of oviposition that are consumed later by uninfected larvae. Another possible source of horizontal transmission in colonies (but not in our experiment) is through contamination of honey when infected and uninfected parasitoids share the same food source. Because T. zealandicus feeds avidly on honey in colony containers this could be a significant source of disease amplification in the generations following establishment of new colonies from the field. Further investigations will be necessary to evaluate the prevalence of the infection in field-collected parasitoids, since laboratory studies indicate that the disease is amplified in culture.

\section{ACKNOWLEDGMENTS}

To JC Piva for allowing us to collect insect samples from his poultry farm and to O Ferreira de Almeida for helping with the samples. 


\section{REFERENCES}

Becnel JJ, Andreadis TG 1999. Microsporidia in insects. In M Wittner, The Microsporidia and Microsporidiosis, American Society for Microbiology, Washington, DC, p. 447-501.

Becnel JJ, Geden CJ 1994. Description of a new species of microsporidia from Muscidifurax raptor (Hymenoptera: Pteromalidae), a pupal parasitoid of muscoid flies. $J$ Euk Microbiol 41: 236-243.

Cantwell GE 1970. Standard methods for counting Nosema spores. Am Bee J 110: 222-223.

Geden CJ, Long SJ, Rutz DA, Becnel JJ 1995. Nosema disease of the parasitoid Muscidifurax raptor (Hymenoptera: Pteromalidae): prevalence, patterns of transmission, management, and impact. Biol Contr 5: 607-614.

Geden CJ, Smith L, Long SJ, Rutz DA 1992. Rapid deterioration of searching behavior, host destruction, and fecundity of the parasitoid Muscidifurax raptor (Hymenoptera: Pteromalidae) in culture. Ann Entomol Soc Am 85: 179-187.

Haque MA, Hollister WS, Wilcox A, Canning EU 1993. The antimicrosporidial activity of albendazole. J Invertebr Pathol 62: 171-177.

Larsson JIR 1988. Identifications of microsporidian genera (Protozoa, Microspora) - A guide with comments on the tax- onomy. Arch Protistenkd 136: 1-37.

Leal TTS, Prado AP, Antunes AJ 1982. Rearing the larvae of the blowfly Chrysomya chloropyga (Wiedemann) (Diptera: Calliphoridae) on oligidic diets. Revta bras Zool 1: 41-44.

Olton GS 1971. Bioecological Studies of Tachinaephagus zealandicus Ashmead (Hymenoptera, Encyrtidae), Parasitoid of Synanthropic Diptera, PhD Thesis, University of California, Riverside, $132 \mathrm{pp}$.

SAS Institute 1992. SAS Users Guide: Statistics, SAS Institute, Cary, NC.

Sheetz R, Goolsby J, Poprawski T 1997. Antibiotic treatment of a Nosema sp. (Protozoa: Microsporidia) infecting the ovaries of a parasitic Encarsia wasp (Hymenoptera: Aphelinindae). Subtropical Plant Sci 49: 50-52.

Sprague V, Becnel JJ, Hazard EI 1992. Taxonomy of the phylum Microspora. Crit Rev Microbiol 18: 285-395.

Undeen AH, Vávra J 1997. Research methods for entomopathogenic Protozoa. In LL Lacey, Manual of Techniques on Insect Pathology, Academic Press, San Diego, p. 117151.

Zchori-Fein E, Geden CJ, Rutz DA 1992. Microsporidioses of Muscidifurax raptor (Hymenoptera: Pteromalidae) and other pteromalid parasitoids of muscoid flies. J Invertbr Pathol 60: 292-298. 